\title{
Enamel Conditioning by Phosphoric Acid and Er.Cr: YSGG Laser Irradiation - EDS and SEM Studies
}

\author{
CATALINA IULIA SAVEANU ${ }^{1}$, OANA TANCULESCU2*, DANIELA ANISTOROAEI'*, OANA DRAGOS ${ }^{3}$, \\ ALEXANDRA ECATERINA SAVEANU ${ }^{1}$, LOREDANA GOLOVCENCU ${ }^{1}$, IRINA BAMBOI ${ }^{1}$, LOREDANA LILIANA HURJ UI ${ }^{1}$ \\ ${ }^{1}$ University of Medicine and Pharmacy Grigore T. Popa, Faculty of Dental Medicine, Department of Surgery, 16 Universitatii Str., \\ 700115, lasi, Romania \\ 'University of Medicine and Pharmacy Grigore T. Popa, Faculty of Dental Medicine, Department of Odontology Periodontology \\ \& Fixed Prosthodontic, 16 Universitatii Str., 700115, lasi, Romania \\ ${ }^{3}$ National Institute of Research-Development for Technical Physics - IFT, Iasi, Romania
}

This study evaluated the effects of ortophosforic acid and Er.Cr: YSGG LASER on human enamel by means of a field emission in-lens scanning electron microscope. The materials used for conditioning the teeth were SE ${ }^{T M} 35 \%$ (Scotchbond ${ }^{T M}$ Etchant Phosphoric Acid) and MG6-MZ6 tips with Er, Cr: YSGG laser, 30\% water, $60 \%$ air, $5.5 \mathrm{~W} / 20 \mathrm{~Hz}$ according to manufacturer's instructions. The acid time of action determines enamel demineralization in all situation. Er.Cr: YSGG laser treatment of non-carious enamel, a laser power of $5.5 \mathrm{~W}$ is found to be the optimal to improve the micromorphology of enamel.

Keywords: scanning electron microscopy, Er, Cr: YSG Glaser, ortophosphoric acid, enamel

One of the elements to take into account in dental restoration is the preparation of the dental surface at the level of the dental structures involved in the adhesion process.

At the enamel level, the main objective is to remove the bacterial plaque from its level (Figures 1-A and B). The presence of the bacterial plaque prevents proper adhesion of the restoration material by making an incorrect micromechanical preparation.
A

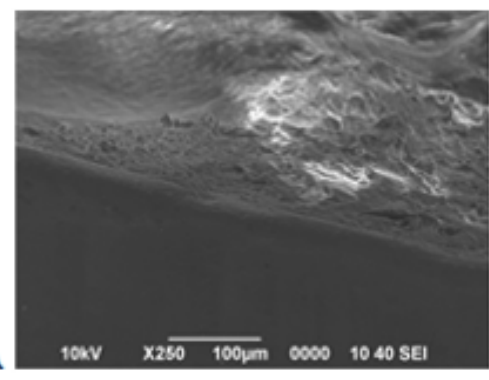

Fig. 1. Bacterial plaque at the enamel level
B

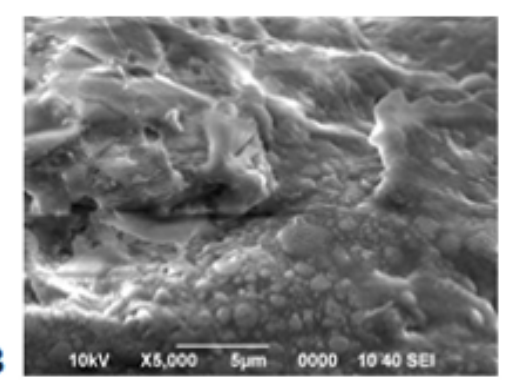

The acidic enamel coating in the protocol of the new adhesive techniques [1,2] aims at providing an optimal surface adhesive monomer impregnation and consists of: removal of the bacterial plaque; removal of residual debris; the creation of micro retention in the form of crypts (Fig.2) [3] by: partial and preferential dissolution of prismatic and interprismatic mineral crystals with the appearance of micro- and macro-retentions (micro-tags and macro-tags) [4]; increasing the free surface energy of the enamel, which facilitates the wetting of the area engraved by the adhesive [5]; providing a larger contact surface between the enamel and the resin [6]. All these objectives aim at obtaining an efficient enamel hybridization by a maximum monomer infiltration, so that the adhesion force value is less dependent on the depth of enamel penetration and more the total contact surface between the resin and the substrate [7]. Controversies in the literature on the conditioning of the enamel substrate have led us to highlight the enamel structure after $35 \%$ orthophosphoric acid in different working times and the application of YSGGlaser (Biolase Waterlase-MD) laser. The null hypothesis was that there are no differences in the structure of the enamel after different times for etching. The testable hypothesis was that there are differences in the structure of the enamel after different times for etching.

\section{Experimental part}

The analysis of the enamel structure by SEM

The enamel structure was analyzed by SEM (Scanning Electron Microscopy) and EDS- (Energy-dispersive X-ray spectroscopy) by JEOLJ SM 6390a J apan. The study was conducted in vitro on human premolar and molars extracted for orthodontic or periodontal reasons, after obtaining informed consent of patients. The samples were stored in a physiological serum, sectioned mesial-distal in the longitudinal direction (diamond discs) finished 400, 600,1200 and 2400 grit SiC paper, polished with gums and abrasive paste $6,3,1$ and $0.25 \mu \mathrm{m}$ under continuous irrigation. The samples were divided in seven groups depending on the type of etching. The materials used for conditioning the teeth were $\mathrm{SE}^{\mathrm{TM}} 35 \%$ (Scotch bond ${ }^{\mathrm{TM}}$ Etchant Phosphoric Acid-3MESPE-Seefeld, Germany) and MG6-MZ6 tipswith Er, Cr: YSGGlaser (Biolase WaterlaseMD), according to manufacturer's instructions, as for enamel $30 \%$ water and $60 \%$ air at $5.5 \mathrm{~W} / 20 \mathrm{~Hz}$. The samples were etched with $\mathrm{H}_{3} \mathrm{PO}_{4} 35 \%$ according to protocol and washing for 10 secondes with distilled water after the Bates et al. [3]. The samples were conditioned as follows: GR.1=SE ${ }^{\mathrm{TM}} 35 \%-5 \mathrm{~S} ; \mathrm{GR} .2=\mathrm{SE}^{\mathrm{TM}} 35 \%-10 \mathrm{~s} ; \mathrm{GR} .3=$ $\mathrm{SE}^{\mathrm{TM}} 35 \%-20 \mathrm{~s} ; \mathrm{GR} .4=\mathrm{SE}^{\mathrm{TM}} 35 \%-30 \mathrm{~s} ; \mathrm{GR} .5=\mathrm{SE}^{\mathrm{TM}} 35 \%-60$ S; GR.6 $=\mathrm{SE}^{\mathrm{T}} 35 \%-120$ s; GR.7= Er. Cr: YSGGlaser irradiating at $30 \%$ water and $60 \%$ air at $5.5 \mathrm{~W} / 20 \mathrm{~Hz}$; The teeth were then stored in saline solution $48 \mathrm{~h}$. SEM and EDS observation was done with JEOLJ SM 6390 J apan.

*email:otanculescu@gmail,com, Phone:+40742044279; cmiortodent@yahoo.com, Phone:+40721377269 


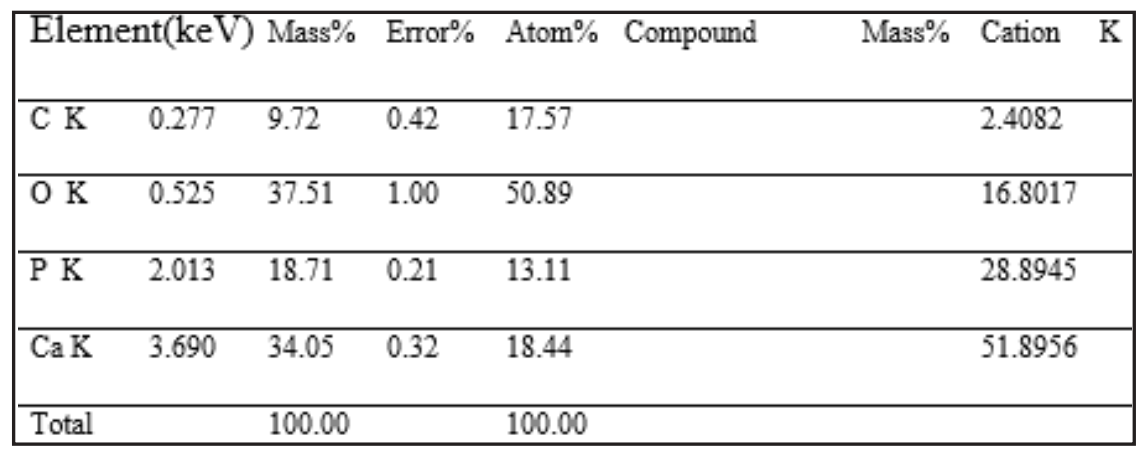

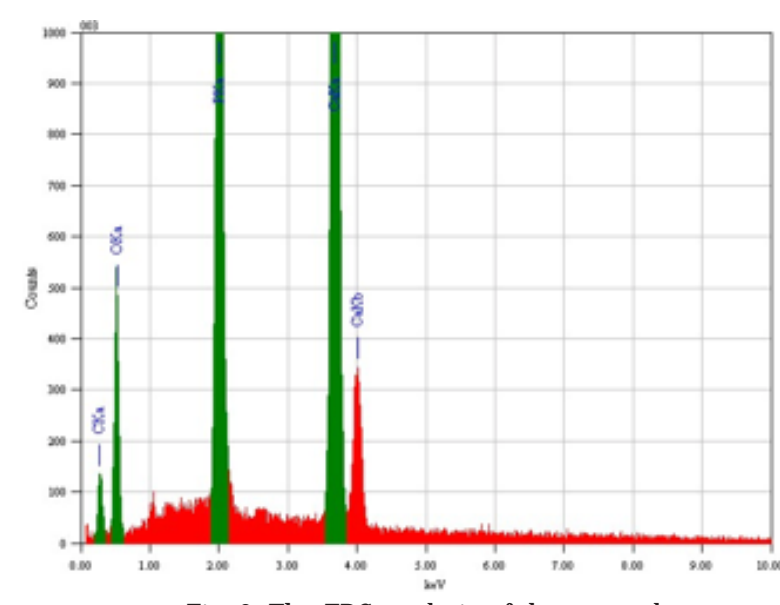

Fig. 2. The EDS analysis of the enamel

\section{Results and discussions}

EDS analysis revealed the structure of enamel is according to the table 1 and figure 2 .

By electronic microscopy studies we highlighted the fact that a time by $5 \mathrm{~s}$ (Figure 3-A), $10 \mathrm{~s}$ (Figure 3-B), $20 \mathrm{~s}$ (Figure 3-C), $30 \mathrm{~s}-\mathrm{D}$ ) is as effective as one performed for $60 \mathrm{~s}$ (Figure 3-E), or $120 \mathrm{~s}$ (Figure 3-F), the enamel attack mode being unchanged by the time of action except the depth of around the enamel prisms.

The technique of total acid etching made for the adhesion of composite resin to enamel has revolutionized the practice of dental restorations. This involves the dissolution of $\mathrm{OH}$-apatite resulting in retention, interprismatic or intraprismatic crypts (Fig.3C).

Regarding the micrographic analysis of the acid treated enamel surface, we highlighted the fact that a 15-sacid is as effective as one performed for $60 \mathrm{~s}$, the enamel attack mode being unchanged by the time of action except the depth around the enamel prisms (Figures 3-F, 3-G). The enamel dissolution is related to the degree of different mineralization (observed betw een the two Retzius striations) and the evolution of the organic components depending on the late maturation stage. The attack of acids is homogeneous between two Retzius striations, but decreases in intensity at striae level. This may be due to the change in the direction of orientation of the prismatic structures inside the strips and due to the composition of the organic matrix, which is a limiting factor for the diffusion of the acid solutions and the destructions they produce.

Studies have shown that the strength of adhesion has not been affected by the demineralization depth. [8]. This study highlights the fact that the adhesion strength of composite resins is not significantly influenced by the type of acid used. (19.7 MPa (Mega Pascal) following $35 \%$ orthophosphoric acid grading,
Table 1

MINERALE COMPOUND OF THE ENAMEL
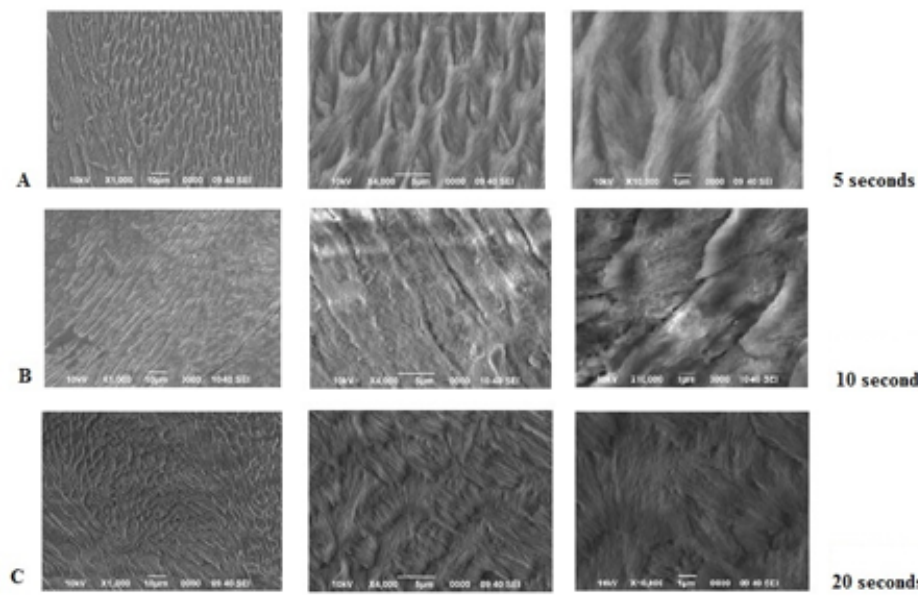

5 seconds
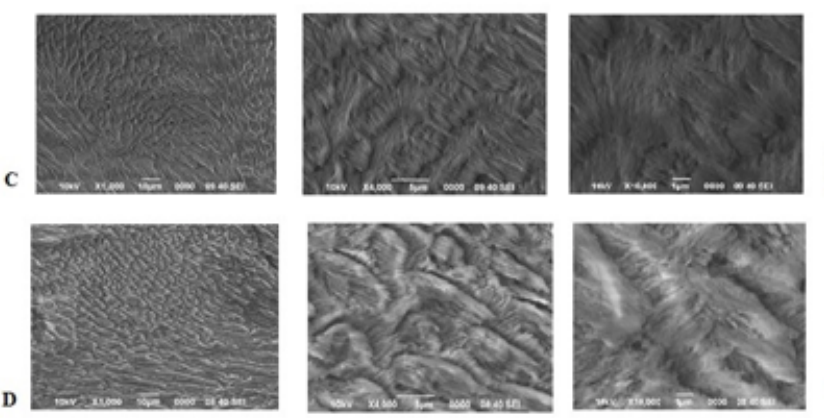

10 seconds
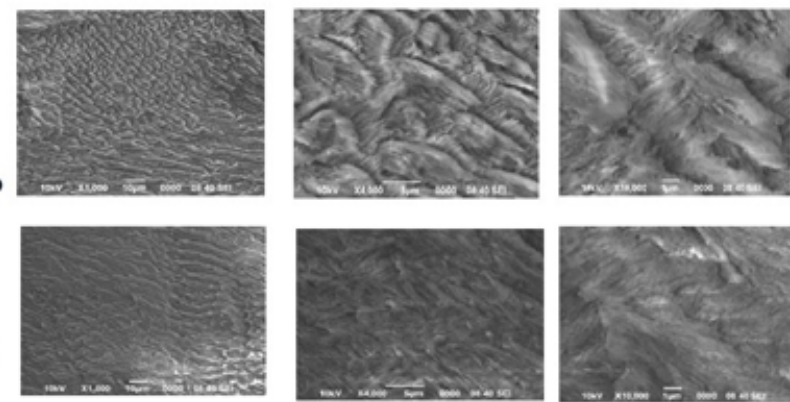

20 seconds
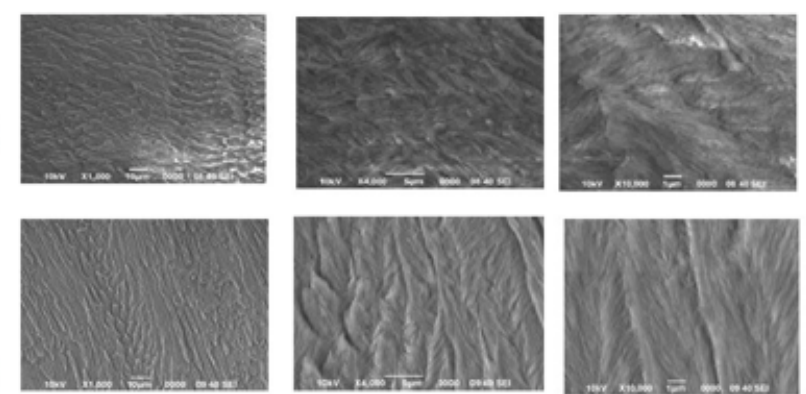

30 seconds
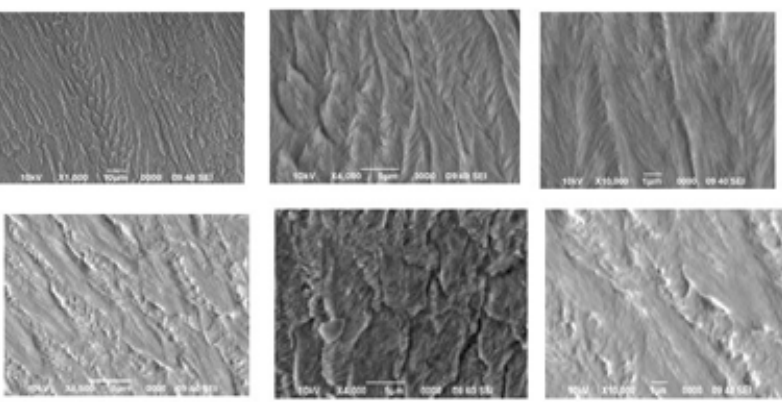

60 seconds

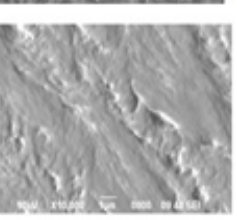

120 seconds

Fig. 3 Top-view SEM photomicrographs of the enamel structure - longitudinal section after etching with $\mathrm{SE}^{\mathrm{TM}} 35 \%$ Scotchbond ${ }^{\mathrm{TM}}$ Etchant Phosphoric Acid-3MESPE-Seefeld, Germany SEMX1 000,SEM X4 000, SEMX10 000 for A-5 s; B-10 s; C-20 s; D-30 s; E-60 s; F-120 s and magnification SEMX4 000,SEM X4 500, SEMX10 000 for G-LASER Er, Cr: YSGGlaser (Biolase Waterlase-MD), it is observed densification of the enamel

18.6 MPa when using $10 \%$ maleic acid in micro filler composites) but is influenced by the type and composition of the restoration material even if they are of the same class Materials (composite) (5.9 MPa 35\% orthophosphoric acid scoring, $15 \mathrm{~s}$ and $3.2 \mathrm{MPa}$ after maleic acid grading - for microfibers and hybrids). Many specialty studies have highlighted various aspects of SEM and EDS and other types of enamel structure tests [918]. 

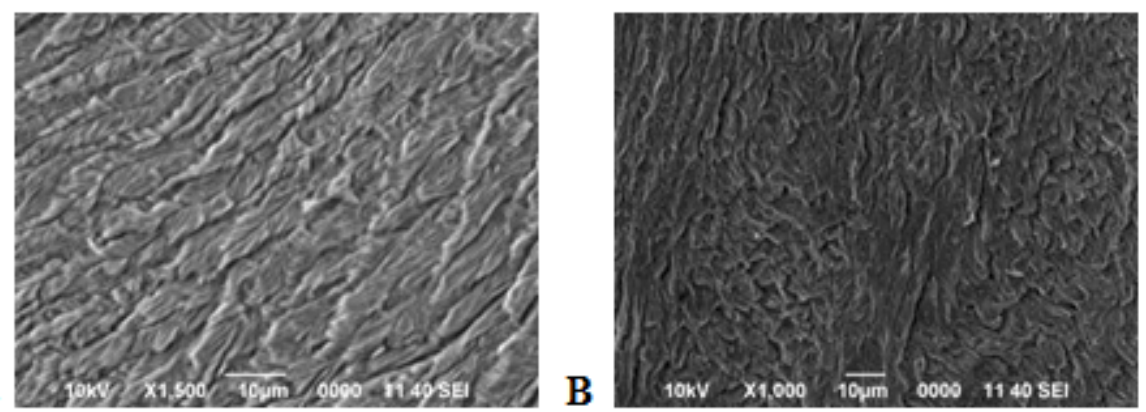

Fig. 4 Top-view SEM photomicrographs of the enamel structure - longitudinal section after etching with $\mathrm{SE}^{\mathrm{TM}} 35 \%$ Scotchbond ${ }^{\text {TM }}$ Etchant Phosphoric Acid3MESPE-Seefeld, Germany Appearance of the enamel structure at the level of the cusps, A-SEMX1,500 and at the level of the cavity side walls towards the base B-SEMX1,000

Also enamel remineralization changes were evaluated in 32 teeth with energy-dispersive X-ray spectroscopy (EDS) and field emission scanning electron microscope (FESEM) [19]. A study which analised demineralized enamel led to a significantly lower margin integrity when the self-etch adhesive I Bond Self Etch was applied, but did not affect margin integrity when the etch-and-rinse adhesives Optibond FL (filled) or Syntac Classic (unfilled) were used [20].

The more or less clear emphasis of the interpersonal structure directs us to apply $35 \%$ orthophosphoric acid for at least $30 \mathrm{~s}$ if a good complication of material is desired in the substructure [21]. Otherwise any demineralization of the substrate and laser treatment favor material retention more in the surface. Where there is no need to do so and the restoration material has a chemical or chemical mechanical adhesion mechanism, adhesion conditions can be ensured. [22].

\section{Conclusions}

Within the limits of the presentstudy, itcan be concluded that the the differences in the structure of the enamel prisms with time and different methods of conditioning are not significant. Er.Cr: YSGG laser treatment of non-carious enamel, a laser pow er of $5.5 \mathrm{~W}$ is found to be the optimal to improve the micromorphology of enamel.

Acknowledgments: This study was supported by the CNCSIS grant budget, no.2669 / 2008 - ideas competition-exploratory research projects.

\section{References}

1.MG BUONOCUORE, A MATSUI, AJ GWINNETT Arch Oral Biol 1968;13:61-70;

2. SORAIA M, GONCALVES M, NONAKA T, DOS SANTOS,J M Braz Dent J 2002 13(1):33-38ISSN 0103-6440;

3.NGO, H, MOUNT GJ, PETERS MCRB, Quintesence Int.1997 28; 63-69; 4.GWINNETT A.J ., MATSUI A. Arch Oral Bioal 1967;12:1615-1620;
5.GWINNETT AJ Arch Oral Biol 1971; 16:731-738., Retief DH J Dent Res 197352:333-341;

6.SWIFT J. EDWARD, Pediatr. Dent., 20:2,80-84, 1998. Swift J. Edward, JADA 1988 9(2):57-60;

7.NAKABAYASHI N, PASHLEY DH TOKYO, Hybridization of dental hard tissue Quintessence Int. 1998;

8.RETIEF DH J Dent Res 1973 52:333-341;

9. PRIYANKA S; PADMAJA S ; GOJE, S. KUMAR; et al. PROGRESS IN ORTHODONTICS 2019 20(18) ;

10.RAMALHO, K. M.; EDUARDO, C. P.; HEUSSEN, N.; et al. CLINICAL ORAL INVESTIGATIONS 2019 23(5) 2103-2112;

11.SHAHRAM S; GHORANNEVISS M, SEYED E MOHAMMAD; et al. MICROSCOPY RESEARCH AND TECHNIQUE 2019 82(4) 421-428;

12.SUCHITRA, J. P.; KALA, A.; SAGADEVAN, S. DJ NB 2019 14(2) 285-290 13.GATIN, E.; MATEI, E.; PIRVU, D.; et al. 2012 7(1) 207-214;

14.PREOTEASA, E. A.; MIHAILESCU, I. N.; PREOTEASA, E. S. DJ NB 2015 10(4): 1161-1180:

15.VIANA, P. S.; ORLANDI, M. O.; PAVARINA, A. C.; et al. CLINICAL ORAL INVESTIGATIONS 2018 22(2):733-744 Published: MAR 2018:

16.YADIRA CEBALLOS-JIMENEZ, ALMA; EMMA RODRIGUEZ-VILCHIS, LAURA; CONTRERAS-BULNES, ROSALIA et al. JOURNAL OF SPECTROSCOPY Article Number: 6750217 Published: 2018:

17.KALLIS, ANTONIS; TOLIDIS, KOSMAS; GERASIMOU, PARIS; et al. LASERS IN MEDICAL SCIENCE 2019 34(1): 23-34;

18.GHIORGHE, C.A., GAMEN, A. C., TIRCA, T., et al., Rev. Chim. (Bucharest), 69, no. 4, p. 2018, p. 921-925

19.ZEGAN, G., CERNEI, E.R., CARAUSU, E., M.,et al. Rev. Chim. (Bucharest), 70, no. 4, p. 1215-1217

20.ZEGAN, G., GOLOVCENCL., CERNEI, E.R., et al., Rev. Chim. (Bucharest), 69, no. 5, 2018, 1244-1246;

21.MEMARPOUR, MAHTAB; SHAFIEI, FERESHTEH; RAFIEE, AZADE et al. BMC ORAL HEALTH 2019 19(92);

22.KORNER, PHILIPP; SULEJ MANI, ALJ MEDINA; WIEDEMEIER, DANIEL B.; et al. ODONTOLOGY 2019 107(3): 308-315

$\overline{\text { Manuscript received: } 19.03 .2019}$ 